\title{
Motivation and adherence to psychosocial treatment for alcohol and drug use-related problems
}

\author{
Motivação e adesão ao tratamento psicossocial \\ entre usuários de substâncias químicas
}

\author{
Jose Carlos de Carvalho LEITE ${ }^{1}$ ID 0000-0001-6310-5828 \\ Maria Fernanda Duarte da LUZ² ID 0000-0002-5001-9776 \\ Júlio Cézar WALZ1 ${ }^{1}$ iD) 0000-0001-9576-2443 \\ Lidiane Isabel FILIPPIN1 (iD) 0000-0003-2043-6162 \\ Ricardo Pedrozo SALDANHA ${ }^{1}$ (iD) 0000-0002-5038-7341 \\ Maria de Lourdes DRACHLER ${ }^{3}$ (D) 0000-0002-7055-8881
}

\begin{abstract}
This is a prospective cohort study of 150 individuals attending a specialized health service for substance-related disorders. The study investigated the association between motivation to remain in treatment and treatment adherence. All service users were interviewed soon after admission to the treatment program and were followed-up during the first two months of treatment. A Cox Regression Model was used to estimate the hazard ratios for dropout during the two months following the admission interview. The results indicated that individuals with a primary-school education, lack of income, and low motivation toward treatment at the admission interview presented a higher risk of treatment dropout. This study showed the importance of motivation in changing addictive behavior and in adherence to treatment as essential factors for recovery.
\end{abstract}

Keywords: Motivation; Substance-related disorders; Treatment outcome.

\section{Resumo}

A associação entre a motivação para manter-se em tratamento e a respectiva adesão foi estudada em uma coorte prospectiva de 150 usuários de um Centro de Atenção Psicossocial-Álcool e Drogas. Modelo de Regressão de Cox foi

$\boldsymbol{v V v V}$

1 Universidade La Salle, Programa de Pós-Graduação em Saúde e Desenvolvimento Humano. Av. Victor Barreto, 2288, 92010-000, Canoas, RS, Brasil. Correspondência para/Correspondence to: J.C.C. LEITE. E-mail: <jcdc.leite@gmail.com>.

2 Clínica Psiquiátrica Santa Tecla. Canoas, RS, Brasil.

3 Governo do Estado do Rio Grande do Sul, Secretaria Estadual da Saúde. Porto Alegre, RS, Brasil.

$\boldsymbol{v} \mathbf{v} \mathbf{v}$

Como citar este artigo/How to cite this article

Leite, J. C. C., Luz, M. F. D., Walz, J. C., Filippin, L. I., Saldanha, R. P., \& Drachler, M. L. (2018). Motivation and adherence to psychosocial treatment for alcohol and drug use-related problems. Estudos de Psicologia (Campinas), 35(4), 389-398. http://dx.doi. org/10.1590/1982-02752018000400006 
usado para estimar as razões de risco para o abandono do tratamento durante os dois primeiros meses após a entrevista de admissão. Os resultados sugerem que a pouca escolaridade (até a $9^{a}$ série), a ausência ou insuficiência de renda, bem como a baixa motivação no momento da entrevista de admissão são fatores de risco para o abandono do tratamento. As motivações para mudar o comportamento aditivo e para aderir ao tratamento foram identificadas como um dos fatores importantes para a recuperação de indivíduos com problemas relacionados ao uso de substâncias químicas.

Palavras-chave: Motivação; Transtornos relacionados ao uso de substâncias; Resultado do tratamento.

The World Health Organization (WHO) considers the abusive use of psychoactive substances to be a chronic and recurrent disease causing worldwide concern. Abuse is likely when individuals have difficulties dealing with stress in everyday contexts, and is often associated with domestic violence, particularly against women (Mangueira, Guimarães, Mangueira, Fernandes, \& Lopes, 2015). Because alcohol is a licit drug used in family celebrations, meetings with friends, and even religious rituals, it has become the most commonly used drug. In Brazil, $68.7 \%$ of the adult population have used alcohol at some point in their lives and $11.2 \%$ are alcoholics; furthermore, the prevalence of the use of other drugs in this age group is $0.5 \%$ for opiates, $0.7 \%$ for cocaine, $2.6 \%$ for marijuana, $0.7 \%$ for amphetamines, and $0.2 \%$ for ecstasy (Peixoto et al., 2010). Therefore, the increase in the use of psychoactive substances has challenged public health policies, causing the Brazilian Ministry of Health to increasingly invest in implementing Centros de Atenção Psicossocial-Álcool e Drogas (CAPS-AD, Psychosocial Care Centers-Alcohol and Drugs).

By decision of the Ministry of Health, CAPS-AD have been implemented in cities with more than 100,000 inhabitants and employ a multidisciplinary team (including a physician, nurse, psychologist, and social worker, as well as nursing technicians and administrative assistants). In these services, first, the patient is welcomed, which is an opportunity to assess physical and psychosocial vulnerabilities. The next step is to develop interventions based on therapeutic plans according to the severity of substance use-related problems: intensive, semiintensive, and non-intensive. In intensive plans, patients receive daily care; in semi-intensive plans, because patients show less suffering than those week; and, in non-intensive plans, care is provided up to three times a month. Hospitalization for detoxification, accompanied by motivational intervention to promote subsequent adherence to psychosocial treatment, is offered to people with chemical dependence and who pose a risk to their own lives and those of others. Therefore, people with psychoactive substance use-related problems and their relatives are guaranteed access by Brazilian Law to care towards resocialization and the reestablishment of social ties (Pitta, Coutinho, \& Rocha, 2015). Despite opportunities to access this type of healthcare, the rate of treatment dropout before completion remains high. For example, after the admission interview and during the first two months, up to $73 \%$ of CAPS-AD users discontinue treatment (Leite, Seminotti, Freitas, \& Drachler, 2011), which presents a continuing challenge for healthcare professionals to keep users motivated to comply with their therapeutic plan.

Motivational variables have been considered robust predictors of human action in healthy and diseased populations (Bandura, 1997; Deci \& Ryan, 2008). Because these variables are modifiable and based on theories (for example, self-efficacy and self-determination theories), they must be assessed when initiating and maintaining health promotion behaviors (Amorim, Ramos, Bento, \& Gazzinelli, 2013; Zemore \& Ajzen, 2014; Schroder, Sellman, Frampton, \& Deering, 2009). Studies suggest that the expectations of patients regarding their recovery process play a key role in the treatment course. These expectations are understood as indications of their personal capacity to perform the necessary actions to reach a proposed goal in a specified time (Bandura, 1997), for example, the self-efficacy expectation of continuing treatment for alcohol and drug use-related problems and the expectation of abstinence or control of addictive behavior (Leite et al., 2011). 
Self-efficacy expectations of performing a desired behavior are key indicators of the motivation for such behavior. These expectations are beliefs (convictions) that one is able to perform behaviors necessary to achieve specific goals (Bandura, 1997). Accordingly, the self-efficacy expectation of treatment adherence refers to the prediction of personal capacity to complete the therapeutic plan in difficult situations, such as when patients feel that they are not reaching their therapeutic goals or when the sessions are too stressful. Conversely, if the treatment in question is abstinence or control of alcohol or drug use, the self-efficacy expectation will be the prediction of personal ability to perform such behavior in situations of risk (including being in the presence of friends while they use alcohol or other drugs). Empirical studies assessing the effectiveness of treatments for chemical dependence have shown evidence of an association between monitoring self-efficacy expectations of treatment adherence and improved therapeutic response in motivational interventions (D'Amico et al., 2015; Miller \& Rollnick, 2012). Therefore, tailoring treatment to user needs and expectations remains a challenge in assessing the effectiveness of these programs (Miller \& Moyers, 2015).

Self-efficacy theory (Bandura, 1997) hypothesizes that the beliefs of individuals regarding their capacity to perform specific activities successfully are a key motivating element in performing such activities. Thus, their beliefs in their skills to overcome obstacles (including situations that present risks for relapse) may influence their commitment to perform specific activities (including adherence to treatment for chemical dependence) and their ability to enjoy the advantages of a healthier life (for example, a life free of substance use-related problems). The present study deepens knowledge on the role of motivation in therapeutic plan completion among adults with chemical dependence-related problems. Specifically, this study examines possible associations between adherence to the therapeutic plan, considering the effects of expectations of social support outside the clinical setting, changing addictive behaviors, and remaining in treatment.

\section{Method}

\section{Study Participants and Design}

Adult (18 years and older) users of a CAPS-AD participated in this prospective cohort study. The CAPS-AD is located in the largest metropolitan region of Southern Brazil and provides services, in agreement with the municipal government, to offer treatment to patients within the Sistema Único de Saúde (SUS, Unified Health System). Initially, the sample size was calculated as 120 individuals, considering an estimated drop-out rate ranging from 30.0 to $50.0 \%$ (Micheletti, Kritski, \& Braga, 2016) in the first six months of treatment, with a $95.0 \%$ confidence level, $80.0 \%$ power, and $1.7 \%$ estimated risk for dichotomous risk factors. Moreover, the initial sample was increased by $25.0 \%$ to allow for a possible lack of information in the records. Individuals in the sample systematically used alcohol, with different severities of dependence. The CAPS-AD professionals and the users participating in the study considered that overcoming the problems related to substance use was the main objective of treatment.

\section{Data Collection}

All users initiating outpatient psychosocial treatment at the CAPS-AD were followed up during the first two months of treatment. Participants were invited to the study by CAPS-AD staff members until the estimated sample size was reached. Program users who accepted the invitation were contacted by a trained interviewer and answered questions on exposure variables, after signing the informed consent form provided by the interviewer, during the first week after admission to treatment. The interview was conducted in the period shortly after admission to enable participants to adjust their expectations regarding the way the health service works. Two months after the first interview, a second data collection was performed to measure the outcomes (dependent variables). 


\section{Measurements}

\section{Dependent variables or outcomes}

Undergoing treatment (yes or no) at the end of the 2nd month after admission and total participation time were the clinical outcomes for the purposes of the present study. These data were collected from medical records. The allocation of participants to one of the categories of exposure variables and treatment time were operationally defined according to the criteria of the CAPS-AD involved in the study. The CAPS-ADs define treatment dropout as user absence from any therapeutic activity of the program for 30 consecutive days.

\section{Exposure variables of interest}

The exposure variables of interest were measured using standardized scales administered to patients by trained interviewers within a week after the admission interview. The following exposure variables were assessed: expectations of social support outside the clinical setting, self-efficacy expectation of changing addictive behaviors, selfefficacy expectation of treatment adherence, and severity of dependence.

"Expectations of social support outside the clinical setting" was measured using a 19-item scale, the Escala de Apoio Social (EAS), which assesses the likelihood of patients receiving different types of support from relatives, friends, or significant others. The original version of this scale, the Medical Outcomes Study's Social Support Scale (MOS), developed by Sherbourne and Stewart (1991), was validated for Brazil by Griep, Chor, Faerstein, Werneck, and Lopes (2005). The items are grouped into five subscales measuring material, affective, emotional, informational, and positive social interaction support. The validation of the Brazilian EAS scale included factor analysis and reliability assessment (Cronbach's alpha coefficients). The factorial structure corresponding to the subscales explained $72 \%$ of the variance. Cronbach's alpha all factors and the item-total scale score correlations ranged from 0.71 to 0.84 . In the present study, "high" or "low" social support (cut-off point established by the median of the total scale score distribution) was considered to examine the possible relationship between this score and the outcomes.

"Self-efficacy expectations of changing addictive behaviors" were measured using the Escala de Autoeficácia para Abstinência de Drogas (EAAD). The original version of the Alcohol Abstinence Self-Efficacy Scale (AASE) (DiClemente, Carbonari, Montgomery, \& Hughes, 1994) was validated for use in Brazil by Freire (2009). The Brazilian version includes 24 items distributed in four subscales assessing the confidence in an individual's ability to refrain from using a chemical in the risk situations described. The first subscale, negative affect, includes items measuring negative intrapersonal and interpersonal evaluations. The second subscale, positive social interactions, consists of items representing social situations in which substance use aims to facilitate interpersonal relationships. The third subscale, concerns with oneself and others, consists of items representing physical discomfort or pain, worries about other people, and cravings for substances. The fourth subscale, abstinence/impulse, represents the willpower to change addictive behaviors. In the validation of the EAAD in a Brazilian sample, the factorial structure corresponding to the four subscales explained $54 \%$ of the variance. Cronbach's alpha coefficients ranged from 0.72 to 0.92 (0.86 for negative affect, 0.82 for positive social interactions, 0.72 for concerns, 0.74 for abstinence/impulse, and 0.92 for total EAAD scores). Considering that the participants in the present study could have concurrent alcohol and drug use-related problems, the questionnaire on self-efficacy expectations of changing addictive behaviors (originally designed for alcohol use) was adapted to circumstances of chemical substance use.

"Self-efficacy expectations of remaining in treatment" were measured by a single question formulated specifically for the present study. The participants were asked to indicate the level of certainty that they would be able to remain in 
treatment, participating in all activities, for at least the next two months. The answers were organized into five categories: I will certainly not be able to participate $(-2)$, I think I will not participate $(-1)$, I do not know (0), I think I will participate $(+1)$, and I will certainly be able to participate $(+2)$.

"Severity of alcohol dependence" was measured using the Short Alcohol Dependence Data (SADD) scale (Raistrick, Dunbar, \& Davidson, 1983), validated for use in Brazil by Rosa-Oliveira et al. (2011). The scale includes 15 self-administered items assessing alcohol consumption. The degree of dependence is estimated into three categories, considering the total scale score: 1 to $9=$ mild dependence, 10 to $19=$ moderate dependence, and higher than $20=$ serious dependence. In the SADD validation in a Brazilian sample, the principal components analysis of the scale explained $69.6 \%$ of data variability; Cronbach's alpha coefficient was 0.79 , suggesting that the items of the scale converge to the same construct (alcohol dependence).

\section{Other exposure variables}

The following data were measured by closeended questions: (a) patients' social and economic conditions, including age, gender, education, income, occupation, housing, and living situation (alone or with others); (b) experiences of previous treatment for chemical substance use-related problems; and (c) psychoactive drugs used.

\section{Statistical Analysis}

The objective of the analysis was to investigate the association between motivation to remain in psychosocial treatment at a CAPS-AD and remaining in treatment two months after the admission interview, which is the outcome of interest of this study. The duration of treatment participation and the outcome predictors were investigated by survival analysis, using the Cox regression model. The duration of treatment participation for participants who remained in treatment for at least two months was censored (interrupted) at the end of the second month, when their follow up by the research study ended.

Hazard ratios of the occurrence of treatment dropout, at each time point in the first two months of treatment, were estimated using univariate (or unadjusted) and multivariate (or adjusted) Cox Regression Models. Each univariate model included the outcome of interest and an exposure variable; each multivariate Cox Regression Model included the exposure variables that showed evidence of effect on the outcome of interest (treatment dropout). A significance level of $5 \%$ was determined as indicating evidence of the effect of exposure variables of interest on the hazard ratio of treatment dropout in the study period. The Statistical Package for the Social Sciences (IBM SPSS Inc., Chicago, IL, EUA) software version 22 was used for data analysis.

\section{Ethical Considerations}

The Research Ethics Committee of University La Salle authorized and monitored the ethical aspects of the study (Opinion $n^{\circ} 663.211$ of 05/26/2014 - CAAE 26300613.0.0000.5307). The participants were only included in the study after signing the informed consent form and were free to withdraw from the study, at any time, without affecting their treatment.

\section{Results}

A total of 150 patients beginning psychosocial treatment for chemical substance use-related problems participated in the study. The second column of Table 1 outlines the distribution of patients according to their social and economic characteristics, previous psychosocial treatments, severity of alcohol dependence at the beginning of treatment, and use of illicit drugs in the previous 30 days. Most participants were men (87.3\%; $n=131 / 150)$ and $12.7 \%$ were women $(n=19 / 150)$. Their age ranged from 19 to 68 years, including $34.7 \%(n=52 / 150)$ of participants who were 19 to 30 years old, $40.6 \%(n=61 / 150)$ from 31 to 40 years old, and $24.7 \%(n=37 / 150)$ from 40 to 68 
years old. Most participants (55.4\%; $n=83 / 150$ ) had only a primary school education, $35.3 \%$ ( $n=53 / 150$ ) had a secondary education, and $9.3 \%$ ( $n=14 / 150)$ had attended college. The majority (73.3\%; $n=110 / 150)$ of participants had no source of income. Social support outside the clinical environment was considered high (higher than the median) for $50.7 \%$ ( $n=76 / 150)$ of participants. Approximately half $(47.3 \% ; n=71 / 150)$ lived alone, whereas the remaining $52.7 \%$ of participants lived with other people. Most participants (64.7\%; $n=7 / 150$ ) had previously taken part in some type of treatment for alcohol or drug use-related problems; the rest $(35.3 ; n=53 / 150)$ were starting treatment for those problems for the first time. Nearly all patients (98.0\%; $n=147 / 150)$ had severe alcohol dependence at the beginning of treatment, whereas the other $2.0 \%(n=3)$, had mild or moderate dependence. Most patients (89.3\%; $n=134 / 150)$ reported the use of illicit drugs in the last month.

Table 1

Characteristics of patients who discontinued treatment

\begin{tabular}{|c|c|c|c|c|c|}
\hline \multirow{2}{*}{ Variables } & \multicolumn{2}{|c|}{ Participants } & \multicolumn{2}{|c|}{ Discontinuation } & \multirow{2}{*}{$p$} \\
\hline & $n$ & $\%$ & $n$ & $\%$ & \\
\hline Gender & & & & & $0.454^{a}$ \\
\hline Male & 131 & 87.3 & 117 & 89.3 & \\
\hline Female & 19 & 12.7 & 16 & 84.2 & \\
\hline Age (years) & & & & & $0.301^{b}$ \\
\hline 1930 & 52 & 34.7 & 44 & 84.6 & \\
\hline $31-40$ & 61 & 40.6 & 57 & 93.4 & \\
\hline $41-68$ & 37 & 24.7 & 32 & 86.5 & \\
\hline Education level & & & & & $<0.001^{b}$ \\
\hline Up to primary & 83 & 55.4 & 80 & 96.4 & \\
\hline Secondary & 53 & 35.3 & 43 & 81.1 & \\
\hline Higher & 14 & 9.3 & 10 & 71.4 & \\
\hline Source of income & & & & & $0.009^{b}$ \\
\hline Yes & 40 & 26.7 & 31 & 77.5 & \\
\hline No & 110 & 73.3 & 102 & 92.7 & \\
\hline Social support outside the clinical setting & & & & & $0.475^{b}$ \\
\hline Highc & 76 & 50.7 & 66 & 86.8 & \\
\hline Low $^{d}$ & 74 & 49.3 & 67 & 90.5 & \\
\hline Living situation & & & & & $0.580^{b}$ \\
\hline Alone & 71 & 47.3 & 64 & 90.1 & \\
\hline With other people & 79 & 52.7 & 69 & 87.3 & \\
\hline Previous treatment & & & & & $0.297^{b}$ \\
\hline No & 53 & 35.3 & 45 & 84.9 & \\
\hline Yes & 97 & 64.7 & 88 & 90.7 & \\
\hline Severity of alcohol dependence & & & & & $0.305^{a}$ \\
\hline Mild to moderate & 3 & 2.0 & 2 & 66.7 & \\
\hline Severe & 147 & 98.0 & 131 & 89.1 & \\
\hline Illicit drug use (last month) & & & & & $0.696^{a}$ \\
\hline No & 16 & 10.7 & 15 & 93.8 & \\
\hline Yes & 134 & 89.3 & 118 & 88.1 & \\
\hline Total & 150 & 100.0 & 133 & 86.7 & \\
\hline
\end{tabular}


Most patients (88.7\%; $n=133 / 150)$ dropped out of the current psychosocial treatment at the CAPS-AD during the first two months of treatment. The third column of Table 1 outlines the number and percentage of participants who dropped out of treatment, according to the exposure variables. The dropout rate decreased with education (chisquared for linear trend, $p<0.001$ ) from $96.4 \%$ $(n=80 / 83)$ for primary education, to $71.4 \%(n=10 / 14)$ for patients with higher education. Having some source of income was also associated with a lower treatment dropout rate (chi-squared, $p=0.009$ ); $77.5 \%$ ( $n=31 / 40$ ) of patients reporting some income dropped out, compared to $92.7 \%(n=102 / 133)$ of those with no source of income. No evidence was found for associations between the psychosocial treatment dropout rate and the following variables: gender (chi-squared, $p=0.454)$, age group $(p=0.301)$, living alone or with other people $(p=0.589)$, social support outside the clinical setting (chi-squared, $p=0.475)$, participation in previous treatment for alcohol or drug-related problems ( $p=0.297)$, severity of alcohol dependence $(p=0.305)$, and illicit drug use in the last month $(p=0.696)$.

At the beginning of treatment, the score for self-efficacy expectations of changing addictive behaviors ranged from 11 to 100, and the score for self-efficacy expectations of remaining in treatment in the first two months ranged from 1 to 5 . Table
2 shows that the self-efficacy expectations of changing addictive behaviors averaged 63.60 for patients who remained in treatment and 39.96 for those who dropped out in the first two months of treatment. Conversely, the self-efficacy expectations of remaining in treatment averaged 4.82 for the group of patients who remained in treatment, and 3.56 for those who dropped out of treatment in that period.

The Cox regression model outlined in Table 3 showed evidence for associations between the two types of self-efficacy expectations and treatment dropout. The treatment dropout rate increased by $3 \%$ with every one-point increase in the score of self-efficacy expectations of changing addictive behaviors $(H R=1.03 ; p=0.021$ after adjusting for the variables outlined in Table 1 and self-efficacy expectations of remaining in treatment). In this model, the dropout rate increased approximately two-fold with every one-point decrease in the score of self-efficacy expectations of remaining in treatment $(H R=2.35 ; p=0.034$, after adjusting for the variables outlined in Table 1 and self-efficacy expectations of changing addictive behaviors).

\section{Discussion}

The present study aimed to examine the association between motivation to continue

Table 2

Self-efficacy expectations at treatment onset according to treatment adherence in the first two months

\begin{tabular}{|c|c|c|c|}
\hline & \multirow{2}{*}{ Participants (n) } & \multicolumn{2}{|c|}{ Self-efficacy } \\
\hline & & Mean & $S D$ \\
\hline \multicolumn{4}{|c|}{ Self-efficacy expectations of changing addictive behaviors ${ }^{1}$} \\
\hline Treatment adherence & 17 & 63.60 & 22.19 \\
\hline Treatment dropout & 133 & 39.96 & 22.40 \\
\hline Total & 150 & 42.64 & 23.53 \\
\hline \multicolumn{4}{|c|}{ Self-efficacy expectations of treatment adherence ${ }^{2}$} \\
\hline Treatment adherence & 17 & 4.82 & 0.53 \\
\hline Treatment dropout & 133 & 3.56 & 1.81 \\
\hline Total & 150 & 3.71 & 1.76 \\
\hline
\end{tabular}

Note: ${ }^{1}$ Total score for the scale of self-efficacy expectations of changing addictive behaviors; ${ }^{2}$ Single question about self-efficacy expectations of treatment adherence; SD: Standard Deviation. 
Table 3

Risk of treatment dropout according to self-efficacy expectations

\begin{tabular}{lcc}
\hline Type of self-efficacy expectations & Unadjusted $\mathrm{HR}^{1}(95 \% \mathrm{Cl})^{3}$ & ${\operatorname{Adjusted~} \mathrm{HR}^{2}(95 \% \mathrm{Cl})^{3}}$ \\
\hline Self-efficacy expectations of changing addictive behaviors & & $1.03(1.004-1.05)$ \\
& $1.03(1.01-1.04)$ & $p=0.021$ \\
Self-efficacy expectations of treatment adherence & $p=0.006$ & $2.04(1.06-3.92)$ \\
& $2.21(1.08-4.51)$ & $p=0.034$ \\
\hline
\end{tabular}

Note: ${ }^{1}$ Unadjusted HR: Ratio between risk rates (hazard ratio) estimated using the Cox Regression Model that includes the outcome variable and the exposure variable of interest; ${ }^{2}$ Adjusted HR: For the other self-efficacy expectations in this table, education level, and source of income; ${ }^{395 \%} \mathrm{Cl}$ : $95 \%$ Confidence Interval.

psychosocial treatment for chemical dependencerelated problems and adherence to this treatment. One hundred and fifty patients were followed up at a CAPS-AD for the first two months of treatment, $88.7 \%$ of whom dropped out of treatment. The following variables showed a significant association with the dropout risk: education, income, self-efficacy expectations of changing addictive behaviors, and self-efficacy expectations of remaining in treatment.

Regarding education, the study indicates that patients with an education up to primary school had a higher risk of treatment dropout than did those who had attended college. This association corroborates findings of other studies on adherence to outpatient treatment for alcohol and drug userelated problems (Micheletti et al., 2016; Sousa, Ribeiro, Melo, Maciel, \& Oliveira, 2013). These studies showed increased difficulties in treatment adherence with decreases in level of education.

Regarding income, the present study indicates that patients without any source of income have a higher risk of treatment dropout (albeit only 2\%) compared with those who have a source of income. Difficulties in social inclusion, due to either low education and income or lack of social support, are a barrier to treatment adherence (Silva, Maftum, \& Mazza, 2014; Varela, Sales, Silva, \& Monteiro, 2016).

Regarding the self-efficacy expectations (or motivation) of changing addictive behaviors, the results showed that less motivated participants had a higher risk of treatment dropout compared to other participants. A similar association was also found regarding the motivation to remain in treatment; that is, less motivated patients had more than double the risk of treatment dropout $(H R=2.35)$ than did the other patients. These results are in line with other studies on adherence to treatment for problems related to alcohol and other chemical substances (Ferreira et al., 2015; Sousa et al., 2013). In these studies, motivation to adhere to treatment was assessed by applying the transtheoretical model of behavior change (Prochaska, DiClemente, \& Norcross, 1992). Their findings showed that low levels of treatment adherence and persistence of addictive behaviors were more commonly found among participants allocated to the contemplation stage, and that significant increases in treatment adherence and changes in addictive behaviors were observed among the most motivated patients (typically allocated to the action stage).

Limitations during the data collection of the present study should be noted and these may have led to data bias. The lack of a venue to perform the interviews or to assess the medical records forced the researchers and staff members to intercalate the visits, thus lengthening the research study time. Another difficulty was the high frequency of incomplete medical records, forcing the researchers to search for such data in interviews with the different reference technicians, according to their shift. 
Despite the high treatment dropout rates at the CAPS-AD, facilitating motivation to change addictive behaviors through treatment adherence remains the most effective strategy to promote general health and improve the quality of life for individuals and communities. This study suggests that research should focus particularly on the interview for admission to the treatment program as a possible approach to adjust patient expectations of treatment results and challenges. Health professionals following this approach are expected to contribute to improved adherence to the therapeutic process. In addition to the value of the welcome (initial approach) in promoting treatment adherence, the present study provides likely evidence for the impact of social inequality on access to healthcare, as shown by the effects of poor access to education and income on treatment adherence failure. Future studies with populationbased designs will be able to further explore such evidence to provide data for public initiatives and policies promoting mental health.

Lastly, the role of motivation in health behavioral change processes is noteworthy. Specifically, self-efficacy and self-determination theories (despite their particularities) are based on a key area of common ground in the understanding of human actions (Ryan \& Deci, 2017). In these theories, humans are regarded as active agents; that is, they have cognitive processes that enable them to make decisions regarding actions. Regarding health promotion, studies integrating the above theories aim to contribute to better understand the mechanisms involved in changing behaviors from risk to protection. For example, in adults with type 2 diabetes Mellitus, the intrinsic motivation to adhere to the practice of physical exercise was mediated by the self-efficacy expectations of performing such behavior (Varming, Hansen, Andrésdóttir, Husted, \& Willaing, 2015). In individuals with heart disease, internal motivation and self-efficacy were identified as key predictors of changes in physical activity after cardiac rehabilitation (Mildestvedt, Meland, \& Eide, 2008). Therefore, (a) studies focusing on the integration between self-efficacy and self-determination theories in motivational interventions and (b) the promotion of social inclusion policies through access to education and income generation may represent key advances in treatment effectiveness for those seeking psychosocial rehabilitation. In this healthcare context, rehabilitation can be understood as a process whereby individuals with limitations are given an enhanced opportunity to restore the best possible level of autonomy in their functioning in the community.

\section{Contributors}

All authors contributed to the conception and design of the study, data analysis and final editing.

\section{References}

Amorim, M. M. A., Ramos, N., Bento, I. C., \& Gazzinelli, M. F. (2013). Intervenção educativa na diabetes Mellitus. Psicologia, Saúde \& Doenças, 14(1), 168-184. Recuperado em março 1, 2017, de http://www.scielo. mec.pt/pdf/psd/v14n1/v14n1a11.pdf

Bandura, A. (1997). Self-efficacy: The exercise of control. New York: W. H. Freeman and Company.

D'Amico, E. J., Houck, J. M., Hunter, S. B., Miles, J. N. V., Osilla, K. C., \& Ewing, B. A. (2015). Group motivational interviewing for adolescents: Change talk and alcohol and marijuana outcomes. Journal of Consulting and Clinical Psychology, 83(1), 68-80. http://dx.doi. org/10.1037/a0038155

Deci, E. L., \& Ryan, R. M. (2008). Self-determination theory: A macrotheory of human motivation, development and health. Canadian Psychology, 49(3), 182-185. http://dx.doi.org/10.1037/a0012801

DiClemente, C. C., Carbonari, J. P., Montgomery, R. P., \& Hughes, S. O. (1994). The alcohol abstinence selfefficacy scale. Journal of Studies on Alcohol, 55(2), 141-148. http://dx.doi.org/10.15288/jsa.1994.55.141

Ferreira, A. C. Z., Capistrano, F. C., Souza, E. B. D., Borba, L. D. O., Kalinke, L. P., \& Maftum, M. A. (2015). Motivações de dependentes químicos para o tratamento: percepção de familiares. Revista Brasileira de Enfermagem, 68(3),474-481. http://dx.doi.org/10. 1590/0034-7167.2015680314i

Freire, S. D. (2009). Evidência de validade da "Escala de Autoeficácia para Abstinência de Drogas" (EAAD) e da "Escala de Situações Tentadoras para Uso de Drogas" (ESTUD) em dependentes de cocaína e crack internados (Dissertação de mestrado não-publicada). Pontifícia Universidade Católica do Rio Grande do Sul, Porto Alegre. 
Griep, R. H., Chor, D., Faerstein, E., Werneck, G. L., \& Lopes, C. S. (2005). Validade de constructo de escala de apoio social do Medical Outcomes Study adaptada para o português no Estudo Pró-Saúde. Cadernos de Saúde Pública, 21(3), 703-714. http://dx.doi. org/10.1590/S0102-311X2005000300004

Leite, J. C. D. C., Seminotti, N., Freitas, P. F., \& Drachler, M. D. L. (2011). The Psychosocial Treatment Expectations Questionnaire (PTEQ) for alcohol problems: Development and early validation. European Journal of Psychological Assessment, 27(4), 228-236. http:// dx.doi.org/10.1027/1015-5759/a000077

Mangueira, S. D. O., Guimarães, F. J., Mangueira, J. D. O., Fernandes, A. F. C., \& Lopes, M. V. D. O. (2015). Promoção da saúde e políticas públicas do álcool no Brasil: revisão integrativa da literatura. Psicologia e Sociedade, 27(1), 157-168. http://dx.doi. org/10.1590/1807-03102015v27n1p157

Micheletti, V. C. D., Kritski, A. L., \& Braga, J. U. (2016). Clinical features and treatment outcomes of patients with drug-resistant and drug-sensitive tuberculosis: A historical cohort study in Porto Alegre, Brazil. PLOS One, 11(8), e0160109. Retrieved March 1, 2017, from http://dx.doi.org/10.1371/journal.pone.0160109

Mildestvedt, T., Meland, E., \& Eide, G. E. (2008). How important are individual counselling, expectancy beliefs and autonomy for the maintenance of exercise after cardiac rehabilitation? Scandinavian Journal of Public Health, 36(8), 832-840. Retrieved March 1, 2017, from http://journals.sagepub.com/doi/ abs/10.1177/1403494808090633

Miller, W. R., \& Rollnick, S. (2012). Motivational interviewing: Helping people change. 3rd ed. New York: Guilford.

Miller, W. R., \& Moyers, T. B. (2015). The forest and the trees: Relational and specific factors in addiction treatment. Addiction, 110(3), 401-413. http://dx.doi. org/10.1111/add.12693

Peixoto, C., Prado, C. H. D. O., Rodrigues, C. P., Cheda, J. N. D., Mota, L. B. T.D., \& Veras, A. B. (2010). Impacto do perfil clínico e sociodemográfico na treatment compliance de pacientes de um Centro de Atenção Psicossocial a Usuários de Álcool e Drogas (CAPSad). Jornal Brasileiro de Psiquiatria, 59(4), 317-321. Recuperado em março 1, 2017, de http://www.scielo. br/pdf/jbpsiq/v59n4/08.pdf

Pitta, A. M. F., Coutinho, D. M., \& Rocha, C. C. M. (2015). Direitos humanos nos Centros de Atenção Psicossocial do Nordeste do Brasil: um estudo avaliativo, tendo como referência o Quality RightsWHO. Saúde em Debate, 39(106), 760-771. http:// dx.doi.org/10.1590/0103-1104201510600030016

Prochaska, J. O., DiClemente, C. C., \& Norcross, J. C. (1992). In search of how people change: Applications to addictive behaviors. American Psychologist, 47, 1102-1114. http://doi/abs/10.3109/108 8460 9309149692? needAccess=true \& journalCode=ijan 18

Raistrick, D., Dunbar, G., \& Davidson R. (1983). Development of a questionnaire to measure alcohol dependence. British Journal of Addiction, 78(1), 8995. http://dx.doi.org/10.1111/j.1360-0443.1983. tb02484.x

Rosa-Oliveira, L. Q., Presti, P. D. F., Antunes, I. R., Carbonari, G. C., Imada, A. C., Maeda, M. Y., . . . Doering-Silveira, J. (2011). Reliability and dimensionality of the Short Alcohol Dependence Data (SADD) questionnaire in a clinical sample of hospitalized patients: Using the SADD in a general hospital setting. Revista Brasileira de Psiquiatria, 33(1), 68-71. Recuperado em março 1, 2017, de http://www.scielo.br/pdf/rbp/v33n1/ aop2010.pdf

Ryan, R. M., \& Deci, E. L. (2017). Self-Determination Theory: Basic psychological needs in motivation, development, and well-being. New York: The Guilford Press.

Schroder, R., Sellman, D., Frampton, C., \& Deering, D. (2009). Youth retention: Factors associated with treatment dropout from youth alcohol and other drug treatment. Drug and A/cohol Review, 28(6), 663-668. http://dx.doi.org/10.1111/j.1465-3362.2009.00076.x

Sherbourne, C. D., \& Stewart, A. L. (1991). The MOS social support survey. Social Science and Medicine, 38(6), 705-714. http://dx.doi.org/10.1016/02779536(91)90150-B

Silva, D. I. D., Maftum, M. A., \& Mazza, V. D. A. (2014). Vulnerabilidade no desenvolvimento da criança: influência dos elos familiares fracos, dependência química e violência doméstica. Texto e Contexto-Enfermagem, 23(4), 1087-1094. http://dx.doi.org/10. 1590/0104-07072014001700013

Sousa, P. F., Ribeiro, L. C. M., Melo, J. R. F. D., Maciel, S. C., \& Oliveira, M. X. (2013). Dependentes químicos em tratamento: um estudo sobre a motivação para mudança. Temas em Psicologia, 21(1), 259-268. http:// dx.doi.org/10.9788/TP2013.1-18

Varela, D. S. S., Sales, I. M. M., Silva, F. M. D., \& Monteiro, C. F. D. S. (2016). Rede de saúde no atendimento ao usuário de álcool, crack e outras drogas. Escola Anna Nery, 20(2), 296-302. http://dx.doi.org/10.5935/1414-8 145.20160040

Varming, A. R., Hansen, U. M., Andrésdóttir, G., Husted, G. R., \& Willaing, I. (2015). Empowerment, Motivation, and Medical Adherence (EMMA): The feasibility of a program for patient-centered consultations to support medication adherence and blood glucose control in adults with type 2 diabetes. Patient Preference and Adherence, 9, 1243-1253. http://dx.doi.org/10.2147/ PPA.S85528

Zemore, S. E., \& Ajzen, I. (2014). Predicting substance abuse treatment completion using a new scale based on the theory of planned behavior. Journal of Substance Abuse Treatment, 46(2), 174-182. http:// dx.doi.org/10.1016/j.jsat.2013.06.011

Received: June 2, 2016

Final version: July 20, 2017

Approved: August 4, 2017 